\title{
STRATEGI PEMBELAJARAN BAHASA MANDARIN PADA MAHASISWA ANGKATAN 2019 PROGRAM STUDI PENDIDIKAN BAHASA MANDARIN
}

\author{
Ina, Bun Yan Khiong, Yoanna Afrimonika \\ Program Studi Pendidikan Bahasa Mandarin FKIP UNTAN \\ Email : yqiang_wen@yahoo.com \\ yoanna94@fkip.untan.ac.id
}

\begin{abstract}
Mandarin is a foreign language that is quite popular to learn nowadays. Many companies require their workers to have the ability to speak Mandarin. Mandarin has its peculiarities in pronunciation, Chinese or Chinese characters, vocabulary, and grammar. Therefore, learning Mandarin as a second language is not the same as copying from learning other foreign languages as a second language. So far, Chinese learning has focused more on how to teach a particular material. However, how students learn to affect their success in learning Mandarin is under study. This research will study the strategies used by students in learning pronunciation, Chinese characters, vocabulary, and grammar. The information obtained through the questionnaire summarizes the learning strategies that students have carried out. The conclusions obtained will be used as a scientific basis for lecturers who support courses related to pronunciation skills, mastery of mandarin letters and vocabulary, and skills in using grammar to provide direction and guidance to students on effective learning strategies.
\end{abstract}

Keywords: Learning Strategy, Pronunciation, Chinese characters, Vocabulary, Grammar.

\begin{abstract}
Abstrak
Bahasa Mandarin merupakan bahasa asing yang cukup populer dipelajari pada saat ini. Hal ini dilatarbelakangi oleh permintaan tenaga kerja yang memiliki kemampuan berbahasa Mandarin. Bahasa Mandarin memiliki kekhasannya sendiri dalam pelafalan, huruf Mandarin atau Hanzi, kosakata dan tata bahasa. Oleh karena itu, pembelajaran bahasa Mandarin sebagai bahasa kedua tidak sama persis atau bukan copy paste dari pembelajaran bahasa asing lainnya sebagai bahasa kedua. Selama ini, pembelajaran bahasa Mandarin lebih berfokus pada bagaimana cara dosen mengajarkan suatu materi tertentu. Aspek bagaimana si mahasiswa belajar kurang diperhatikan, sehingga keberhasilan mahasiswa dalam mempelajari bahasa Mandarin juga ikut terpengaruh. Penelitian ini akan difokuskan pada strategi yang digunakan mahasiswa dalam belajar pelafalan, huruf Mandarin, kosakata dan tata bahasa. Informasi yang diperoleh lewat kuesioner diharapkan dapat memberikan rangkuman tentang strategi-strategi pembelajaran yang telah dilakukan oleh mahasiswa. Kesimpulan yang didapat akan digunakan sebagai dasar ilmiah kepada dosen pengampu mata kuliah yang berkaitan dengan keterampilan pelafalan, penguasaan huruf mandarin dan kosakata serta keterampilan penggunaan tata bahasa untuk memberikan arahan dan bimbingan kepada mahasiswa tentang strategi belajar yang efektif.
\end{abstract}

Kata Kunci : Strategi Belajar; Pelafalan; Huruf Mandarin; Kosakata; Tata Bahasa. 


\section{PENDAHULUAN}

Dewasa ini, penulis masih menemukan masyarakat masih mempunyai persepsi bahwa bahasa Mandarin merupakan bahasa yang sangat sulit untuk dipelajari. Beberapa pelajar menggunakan cara dan strategi yang salah dalam mempelajari bahasa Mandarin. Sehingga tingkat kesulitan untuk menguasai bahasa ini semakin tinggi dan semakin terasa sulit. Namun, masyarakat menyadari bahwa pada saat ini penguasaan bahasa asing, terutama bahasa Mandarin mempunyai peranan penting untuk mendapatkan pekerjaan yang lebih baik. Dengan menguasai bahasa Mandarin, seseorang memiliki keterampilan "lebih" dari orang lain. Sekarang ini telah banyak lowongan pekerjaan yang mengharuskan pelamar menguasai Bahasa Mandarin dan kesempatan kerja dalam bidang yang berkaitan dengan bahasa Mandarin masih sangat luas. Hal ini secara tidak langsung mendorong sekolah-sekolah, perguruan tinggi dan institusi untuk membuka kelas bahasa Mandarin.

Dalam mempelajari Bahasa Mandarin, pembelajar perlu menguasai empat aspek pengetahuan berbahasa yaitu pelafalan, aksara mandarin, kosakata, dan tata bahasa. Bagi pembelajar bahasa Mandarin di Indonesia, bahasa Mandarin menjadi salah satu bahasa yang sulit untuk dipelajari. Hal ini berkaitan dengan aksaranya dan pelafalannya yang menggunakan nada. Dalam kedua hal ini antara bahasa Indonesia dan bahasa Mandarin mempunyai perbedaan yang signifikan.

Untuk menguasai pengetahuan tersebut diperlukan pengajaran yang baik serta cara belajar yang baik pula, karena di dalam pembelajaran ada 3 hal penting yang perlu diperhatikan juga, yaitu "Mengajarkan apa?", "Bagaimana mengajarkannya", dan "Bagaimana belajarnya ". Jika kita kaitkan dengan bahasa Mandarin, mengenai "mengajarkan apa", hal ini berhubungan dengan materi pembelajaran bahasa mandarin yang diajarkan oleh guru / dosen; dan "bagaimana mengajarkannya", berhubungan dengan metode seperti apa yang diterapkan oleh guru / dosen untuk meningkatkan hasil pembelajaran bahasa mandarin; sedangkan"bagaimana belajarnya", hal ini berhubungan dengan karakteristik dan cara yang digunakan pembelajar untuk menguasai bahasa Mandarin tersebut.

Sebagai tolak ukur keberhasilan guru / dosen dalam mengajarkan bahasa mandarin, selain memperhatikan materi yang diajarkan serta metode pembelajaran yang digunakan, perlu juga memahami karakteristik serta strategi belajar yang digunakan oleh pembelajar dalam menguasai bahasa mandarin. Dengan memahami cara belajar mereka, maka akan membantu guru / dosen dalam menentukan metode yang paling efektif dalam mengajar yang sesuai dengan cara belajar pembelajar, dan guru/dosen dapat membimbing pembelajar agar strategi yang digunakan memberikan hasil yang lebih maksimal.

Dalam penelitian ini, kami memilih Mahasiswa Program Studi Pendidikan Bahasa Mandarin Angkatan 2019 yang terdiri dari mahasiswa kelas A dan kelas B sebagai objek penelitian kami. Penelitian dilakukan dengan menggunakan metode survey, yaitu dengan meminta responden untuk menjawab serangkaian pertanyaan dalam bentuk kuesioner yang dibagikan kepada responden melalui google form.

Adapun masalah yang ingin kami teliti pada Mahasiswa Angkatan 2019 Program Studi Pendidikan Bahasa Mandarin Universitas Tanjungpura adalah sebagai berikut: (1) Apa saja strategi pembelajaran yang digunakan mahasiswa Angkatan 2019 Prodi Pendidikan Bahasa Mandarin Untan untuk meningkatkan kemampuan mereka dalam penguasaan keterampilan Bahasa Mandarin?; (2) Apa saja kesulitan yang dialami oleh mahasiswa Angkatan 2019 Prodi Pendidikan Bahasa Mandarin website: http://jurnal.untan.ac.id/index.php/jvip 
Untan dalam mempelajari Bahasa Mandarin yang meliputi empat aspek: Pelafalan, Aksara Mandarin, Kosakata dan Tata Bahasa?

Tujuan dari penelitian ini adalah: (1) Dapat mengetahui secara mendalam kondisi dan karakter mahasiswa dalam mempelajari Bahasa Mandarin; (2) Mengetahui kesulitan-kesulitan apa saja yang sering mereka alami dalam proses pembelajaran Bahasa Mandarin; (3) Sebagai referensi dalam memberikan masukan dan saran mengenai metode pembelajaran yang lebih efektif untuk mahasiswa agar dapat menguasai ilmu Bahasa Mandarin secara keseluruhan dan efektif.

\section{.METODE}

Penelitian ini bersifat kualitatif yaitu pengumpulan data dilakukan dalam bentuk kuesioner. Materi kuisioner yang akan diujikan meliputi empat aspek pengetahuan umun yang harus dipelajari dalam Bahasa Mandarin, yaitu : Pelafalan (语音), Aksara Mandarin (汉字), Kosakata (生词), dan Tata Bahasa (语法). Penelitian ini ditujukan untuk mahasiswa Angkatan 2019 Kelas A dan B Program Studi Pendidikan Bahasa Mandarin Fakultas Keguruan dan Ilmu Pendidikan Universitas Tanjungpura Pontianak. Total Mahasiswa sebanyak 33 mahasiswa yang terdiri dari Kelas A sebanyak 18 mahasiswa dan Kelas B sebanyak 15 mahasiswa.

\section{HASIL DAN PEMBAHASAN}

Penelitian ini dilaksanakan pada mahasiswa Prodi Pendidikan Bahasa Mandarin Angkatan 2019 kelas A dan kelas B. Tujuan dari penelitian ini adalah ingin mengetahui secara mendalam mengenai strategi pembelajaran yang sering dilakukan mahasiswa guna untuk meningkatkan kemampuan dalam menguasai ke empat aspek berbahasa Mandarin yaitu antara lain: Pelafalan, Kosakata, Aksara Mandarin, dan Tata bahasa. Selain itu juga ingin mengetahui hambatan serta kesulitan yang dialami mahasiswa angkatan 2019 dalam mempelajari bahasa Mandarin. Pengambilan data dilakukan menggunakan aplikasi google form dikarenakan situasi sekarang ini yang sedang pandemi sehingga membuat para mahasiswa dan dosen tidak dapat melakukan tatap muka secara langsung, jadi cara alternatif yaitu menggunakan aplikasi online untuk mendukung proses pengambilan data penelitian. Google Form dibagikan kepada mahasiswa dari tanggal 25 Juni s.d 27 Juni 2020. Dari hasil penelitian diperoleh tiga kelompok data yaitu data terkait informasi mahasiswa, data terkait pengalaman belajar mahasiswa, dan data hasil kuisioner terkait dengan strategi pembelajaran mahasiswa dalam 4 aspek pembelajaran bahasa Mandarin yaitu Pelafalan, Kosakata, Aksara Mandarin dan Tata Bahasa. Berikut ini adalah hasil data kuisioner peneliti kepada mahasiswa. Informasi Umum terkait Responden

Kuesioner dibagikan kepada responden dengan menggunakan google form dengan link https://forms.gle/QpgzkFnkjjF4jzL16 pada tanggal 25-26 Juni 2020 dengan jumlah responden 31 mahasiswa, dengan komposisi responden sebagai berikut:

a. Berdasarkan jenis kelamin: Laki-laki berjumlah 5 mahasiswa, sedangkan perempuan berjumlah 26 mahasiswa.

b. Berdasarkan suku bangsa: Suku Chinese ada 20 mahasiswa sedangkan Suku Non Chinese ada 11 mahasiswa.

c. Berdasarkan kelas: Kelas A berjumlah 16 mahasiswa, sedangkan kelas B berjumlah 15 mahasiswa.

d. Berdasarkan umur: Mahasiswa yang berumur 18 tahun ada 9 mahasiswa, berumur 19 tahun ada 19 mahasiswa, sedangkan yang berumur 20 tahun ada 3 mahasiswa.

e. Berdasarkan kemampuan HSK: Tingkat tes hsk yang tertinggi dari mahasiswa angkatan 2019 itu adalah Tes HSK Level 4 yaitu ada 2 
mahasiswa, yang pernah mengikuti tes HSK Level 3 ada 3 mahasiswa, yang pernah mengikuti tes HSK Level 2 hanya 1 mahasiswa, sedangkan sisanya yaitu 25 mahasiswa menyatakan bahwa mereka belum pernah sama sekali mengikuti tes HSK di semua level.

\section{Informasi terkait Pengalaman Belajar Responden}

a. Lamanya belajar bahasa Mandarin: Berkaitan dengan lamanya waktu belajar bahasa Mandarin, dari 31 responden didapati hasil sebagai berikut: terdapat 15 mahasiswa yang baru belajar selama bahasa Mandarin selama 6-1 tahun; 5 mahasiswa yang sudah belajar selama 1-2 tahun; 1 orang yang telah belajar selama 2-3 tahun: serta terdapat 10 mahasiswa yang sudah belajar bahasa Mandarin diatas 3 tahun.

b. Alasan mahasiswa belajar bahasa Mandarin: Alasan mahasiswa belajar bahasa Mandarin yang memiliki presentase paling tinggi yaitu sebesar $87,1 \%$ adalah "bahwa bahasa mandarin sangat membantu untuk di masa yang akan datang"; presentase alasan belajar bahasa Mandarin tertinggi kedua yaitu sebesar $64,5 \%$ adalah "karena mereka tertarik dengan bahasa Mandarin"; presentase tinggi ketiga adalah "agar nantinya bisa bersekolah di China" sebesar 58,1\%; presentase tinggi keempat adalah "karena mereka tertarik dengan Kebudayaan Tiongkok" yaitu sebesar 32,3\%; sedangkan alasan belajar bahasa mandarin yang memiliki presentase dibawah $30 \%$ yaitu antara lain: "agar bisa berwisata dan tinggal di China", "permintaan dari orangtua" serta ada 1 mahasiswa yang menambahkan alasan lain yaitu alasannya belajar bahasa mandarin adalah "karena termotivasi dari orang yang telah belajar bahasa Mandarin".

c. Pentingnya belajar bahasa Mandarin: dari 31 responden terdapat 21 mahasiswa $(67,7 \%)$ beranggapan "SANGAT PENTING" mempelajari bahasa mandarin; dan terdapat 9 mahasiswa (29\%) yang beranggapan "PENTING" mempelajari bahasa mandarin; sedangkan terdapat 1 mahasiswa $(3,2 \%)$ yang beranggapan bahwa pentingnya belajar bahasa mandarin itu "BIASA SAJA".

d. Masalah terbesar yang sering dihadapi mahasiswa dalam mempelajari bahasa Mandarin: dari 31 responden diperolah hasil bahwa masalah terbesar yang sering dihadapi dalam belajar bahasa mandarin yaitu pelafalan dan nada yang kurang tepat dan penguasaan tata bahasa yang kurang baik memiliki presentase yang sama yaitu 77,4\%; penguasaan kosakata yang masih sedikit $(54,8 \%)$; kesulitan dalam mengingat tulisan aksara bahasa mandarin (48,8\%); masih memerlukan bantuan hanyu pinyin dalam membaca tulisan aksara mandarin (35,5\%); Kemampuan dasar serta pelafalan yang kurang baik $(32,3 \%)$; kesulitan dalam menghafal kosakata (25,8\%); serta sebanyak $(3,2 \%)$ responden beranggapan bahwa masih sering bermasalah dengan tata bahasa terutama dalam menyusun tata bahasa dalam sebuah kalimat. 


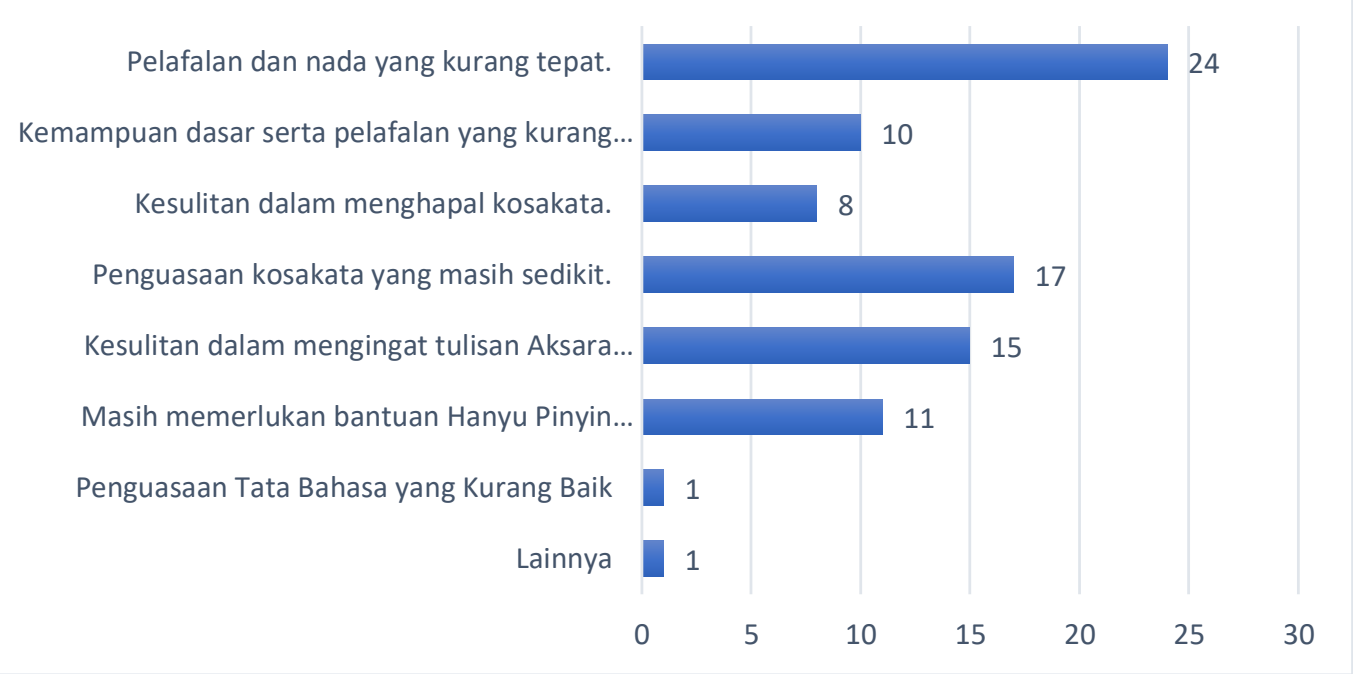

Gambar 1. Kesulitan dalam Belajar Bahasa Mandarin

e.Penghambat mahasiswa dalam meningkatkan kemampuan menguasai bahasa Mandarin: penghambat terbesar dalam meningkatkan kemampuan menguasai bahasa Mandarin berdasarkan presentase paling tinggi sampai yang terendah yaitu: kurangnya lingkungan belajar bahasa Mandarin
(80,6\%); kurangnya waktu latihan bagi diri sendiri (71\%); minimnya fasilitas pembelajaran sebagai penunjang keberhasilan belajar $(48,4 \%)$; kurangnya motivasi yang diberikan oleh dosen $(9,7 \%)$; serta terakhir karena kurang giatnya dalam belajar bahasa mandarin $(3,2 \%)$.

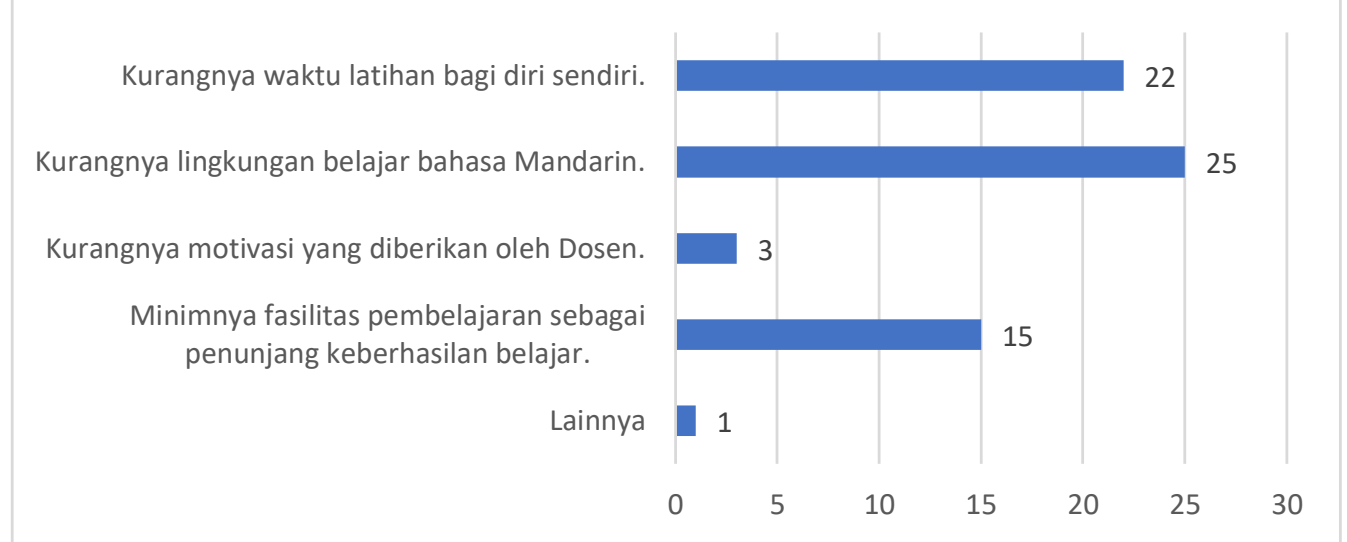

Gambar 2. Faktor Penghambat dalam belajar bahasa Mandarin

\section{Hasil terkait strategi dan kesulitan responden dalam pembelajaran Tata bahasa Mandarin}

Berdasarkan hasil kuisioner yang telah diisi oleh responden, sehingga diperoleh data strategi pembelajaran yang digunakan oleh mahasiswa dalam memahami dan menguasai Tata Bahasa Mandarin adalah sebagai berikut: 


\begin{tabular}{|c|c|c|c|c|c|c|c|c|c|c|c|c|c|}
\hline \multicolumn{3}{|c|}{ SOAL } & 1 & 2 & 3 & 4 & 5 & 6 & 7 & 8 & 9 & 10 & $\begin{array}{c}\% \\
\text { Rata2 }\end{array}$ \\
\hline \multirow{9}{*}{ 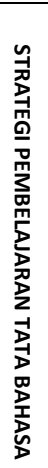 } & \multirow{9}{*}{$\begin{array}{l}\text { ग } \\
\text { 男 } \\
\mathbf{2}\end{array}$} & \multirow{2}{*}{ SS } & 1 & 3 & 4 & 6 & 5 & 10 & 16 & 8 & 5 & 5 & \multirow{2}{*}{$19,09 \%$} \\
\hline & & & $3,03 \%$ & $9,09 \%$ & $12,12 \%$ & $18,18 \%$ & $15,15 \%$ & $30,30 \%$ & $48,48 \%$ & $24,24 \%$ & $15,15 \%$ & $15,15 \%$ & \\
\hline & & \multirow{2}{*}{$\mathbf{S}$} & 8 & 16 & 11 & 20 & 18 & 15 & 16 & 18 & 13 & 12 & \multirow{2}{*}{$44,55 \%$} \\
\hline & & & $24,24 \%$ & $48,48 \%$ & $33,33 \%$ & $60,61 \%$ & $54,55 \%$ & $45,45 \%$ & $48,48 \%$ & $54,55 \%$ & $39,39 \%$ & $36,36 \%$ & \\
\hline & & \multirow{2}{*}{$\mathbf{N}$} & 20 & 12 & 15 & 7 & 9 & 8 & 1 & 7 & 15 & 15 & \multirow{2}{*}{$33,03 \%$} \\
\hline & & & $60,61 \%$ & $36,36 \%$ & $45,45 \%$ & $21,21 \%$ & $27,27 \%$ & $24,24 \%$ & $3,03 \%$ & $21,21 \%$ & $45,45 \%$ & $45,45 \%$ & \\
\hline & & \multirow{2}{*}{ TS } & 4 & 1 & 3 & 0 & 1 & 0 & 0 & 0 & 0 & 1 & \multirow{2}{*}{$3,03 \%$} \\
\hline & & & $12,12 \%$ & $3,03 \%$ & $9,09 \%$ & $0,00 \%$ & $3,03 \%$ & $0,00 \%$ & $0,00 \%$ & $0,00 \%$ & $0,00 \%$ & $3,03 \%$ & \\
\hline & & STS & 0 & 1 & 0 & 0 & 0 & 0 & 0 & 0 & 0 & 0 & $0,30 \%$ \\
\hline
\end{tabular}

\section{Tabel Presentase Penggunaan Strategi dalam Meningkatkan Tata Bahasa Mandarin}

Berdasarkan tabel diatas, dapat diketahui bahwa presentase rata-rata penyataan "SANGAT SETUJU" dan "SETUJU" masing-masing yaitu 19,09\% dan 44,55\%. Dari keduanya dapat diketahui bahwa ada $63,64 \%$ mahasiswa telah menggunakan beberapa strategi pembelajaran untuk meningkatkan perbendaharaan Tatabahasa Bahasa Mandarin mereka. Selain itu ada 33,03\% mahasiswa menyatakan "NETRAL/BIASA SAJA" akan strategi yang digunakan, sehingga dapat diketahui bahwa mereka tidak begitu sering menggunakan strategi tersebut. Sedangkan hanya terdapat $3,03 \%$ mahasiswa menyatakan "TIDAK SETUJU" akan strategi pembelajaran Tatabahasa yang diberikan. Adapun terdapat 1 responden yang menyatakan pernyataan "SANGAT TIDAK SETUJU" terkait satu strategi/cara yang digunakan yaitu "Mencari persamaan struktur Bahasa Mandarin dengan bahasa Ibu" Hal ini membuktikan bahwa mereka tidak menggunakan strategi tersebut dalam meningkatkan kemampuan penguasaan Tatabahasa Bahasa Mandarinnya.

Dari tabel diatas, dapat pula diketahui strategi/cara yang paling sering mereka gunakan adalah Strategi metakognitif dan Strategi sosial yaitu pada soal: No.4 "Mencari referensi lain untuk menambah pemahaman tentang materi struktur Bahasa yang dipelajari”; No.5 "Berpikir untuk memecahkan masalah dan memperoleh manfaat dari proses belajar materi struktur Bahasa yang dipelajari"; No.8 "Meningkatkan pengetahuan budaya Bahasa Mandarin."; Sedangkan strategi/cara yang kadang-kadang mereka lakukan adalah Strategi kognitif yaitu pada soal no.1 "Mampu mengunakan struktur Bahasa Mandarin yang baru".

Berdasarkan soal essai yang diberikan oleh responden, diketahui bahwa cara/strategi yang paling banyak mahasiswa lakukan untuk menguasai sebuah Tatabahasa bahasa mandarin adalah strategi kognitif, metakognitif dan Strategi sosial. Adapun beberapa kutipan pernyataan dari responden sebagai berikut:

"Cara saya selama mempelajari tata bahasa mandarin adalah dengan menonton film mandarin dan banyak membaca agar memperbanyak kosakata mandarin"; "Cara saya mempelajari tata bahasa mandarin yaitu dengan membaca buku paket dan dengan menonton film"; "Mendengarkan lagu, menonton film/drama dalam bahasa 
Mandarin, untuk materi pembelajaran biasanya saya mengulangi pelafalan dan mencari referensi lain untuk menambah wawasan tata bahasa Mandarin"; "Dalam belajar bahasa baru saya lebih banyak membaca suatu teks secara berulang dan menghafalnya,apabila susah dimengerti saya tulis pinyinnya dan apabila masih belum mengerti saya bertanya kepada teman-teman yg lebih pandai,untuk menulis hanzi saya tulis biasanya satu buku satu hanzi agar lebih mudah menghafalnya"; "Dalam mempelajari tata bahasa Mandarin biasanya saya kaitkan dengan bahasa ibu seringkali hal itu dapat mempermudah saya dalam mengingat dan menguasai tata bahasa yang benar"; "Menganalisis kaidahkaifah kebahasaan melalui buku dan penjelasan dari dosen";

\section{a. Kesulitan yang dihadapi dan usaha yang dilakukan}

Berdasarkan soal essai yang diberikan, diketahui bahwa mahasiswa kurang menguasai penggunaan Tatabahasa dan penempatan Tatabahasa tersebut. Adapun beberapa kutipan pernyataan dari responden sebagai berikut: "Kesulitan yang saya rasakan selama mempelajari Tata Bahasa Mandarin ialah mengenai cara pemakaiannya dan juga penempatan tata bahasa tersebut ke dalam kalimat yang tepat"; "Terdapat beberapa tata bahasa yang mungkin kita tidak terlalu memahami artinya sehingga membuat kita seringkali salah dan terdapat tata bahasa yang memiliki banyak penggunaannya"; "Biasanya sulit dalam menentukan urutan kata dalam membuat kalimat"; "Kurang mengerti dalam penggunaan tata bahasa Mandarin dan merealisasikannya di kehidupan nyata saat berbicara; Hal ini dikarenakan mereka kesulitan untuk memahami dan kurang mengerti susunan Tatabahasa yang dipelajari, sehingga sulit untuk direalisasikan dalam percakapan seharihari.

Selanjutnya, berdasarkan kesulitan diatas dan hasil soal essai yang diberikan, maka diperoleh cara maupun usaha yang dilakukan dalam mempelajari Tatabahasa Mandarin, diantaranya : menanyakan kepada teman yang lebih menguasai, menggunakan kamus atau software yang mendukung dan secara langsung bertanya kepada Dosen yang bersangkutan. Adapun beberapa kutipan pernyataan dari responden sebagai berikut: "Ketika saya mengalami kesulitan seperti demikian, seringkali saya mengkaitkannya dengan bahasa ibu, kemudian saya bertanya kepada orang yang lebih mengerti dan saya pelajari lebih dalam tentang tata bahasa tersebut dan saya mencoba untuk mencari sumber-sumber yang bisa memberikan saya pengetahuan lebih tentang tata bahasa tersebut"; "Biasanya saya bertanya ke teman yang lebih mengerti atau mencari di referensi lain, menggunakan pleco/google translate"; "Perbanyak kosa kata dan mempelajari struktur bahasanya agar mudah dalam membuat kalimat"; "Mengkaji semua perbedaan arti,fungsi dan letak dalam sebuah tata bahasa"; "Lebih banyak mencari informasi dan referensi belajar yang lain yang dapat membantu";

\section{b. Ketertarikan dalam mempelajari Tatabahasa Mandarin}

Berdasarkan soal essai yang diberikan, diketahui bahwa mahasiswa merasa sangat penting untuk mempelajari sebuah Tatabahasa. Dengan mempelajari Tatabahasa secara benar dapat berkomunikasi dengan baik, sehingga memahami maksud dari sebuah informasi. Mahasiswa mengemukakan bahwa Tatabahasa Mandarin unik, meskipun begitu rumit tapi tetap berusaha keras untuk mempelajarinya, lagipula sekarang telah mengambil jalur pendidikan Bahasa mandarin sehingga pemahaman Tatabahasa harus lebih baik 
lagi. Bahasa Mandarin merupakan salahsatu Bahasa Internasional, dimana kedepan bisa melanjutkan studi di Tiongkok, menjadi tenaga pendidik yang berkompeten, fasih berkomunikasi dengan orang Tiongkok sebuah perusahaan sebagai translator. Adapun beberapa kutipan pernyataan dari responden terkait ketertarikan dalam mempelajari Tatabahasa Mandarin: "Yang membuat saya tertarik dalam mempelajari tata bahasa adalah ketika kita bisa menguasainya maka kita dapat berbicara dengan berbagai variasi kalimat"; "Bahasa yang sangat unik"; "Jika saya mempelajari tata bahasa, kedepannya saya dapat menggunakan bahasa dengan baik dan benar"; "Karena Menurut saya itu hal yang penting dalam mempelajari bahasa mandarin"; "Yang membuat saya tertarik untuk mempelajari tata bahasa ialah rasa kemauan saya untuk memperbaiki tata bahasa saya secara pribadi sehingga hal itu yang membuat saya tertarik untuk mempelajari tata bahasa agar dapat memperbaiki tata bahasa yang saya miliki menjadi lebih baik; "Ingin melanjutkan study ke china"; "Tentunya sangat penting karena ketika kita menguasai tata bahasa maka kita dapat berbicara dengan baik dalam bahasa Mandarin. Mungkin jika untuk berbicara sehari-hari tatabahasa terasa tidak terlalu penting karena di dalam bahasa sehari-hari ketika orang sudah mengerti itu sudah cukup; tetapi jika kita ingin bekerja yang di mana pekerjaan tersebut dibutuhkan cara berbahasa yang formal, kita perlu mempelajari tata bahasa dengan baik agar kita dapat bekerja dengan baik"; "Sangat penting karna sdah termasuk $d$ kancah internasional",

\section{SIMPULAN DAN SARAN Simpulan}

Berdasarkan hasil data penelitian yang dilakukan kepada mahasiswa prodi pendidikan bahasa mandarin Angkatan
2019 dapat disimpulkan bahwa strategi pembelajaran dalam berbahasa mandarin sangat penting terutama dalam menguasai keempat aspek pembelajaran berbahasa yaitu pelafalan, kosakata, hanzi, dan tata bahasa. Selain itu ketertarikan dalam mempelajari bahasa mandarin juga merupakan faktor yang penting sebagai motivasi dalam belajar bahasa mandarin.

Berikut disimpulkan secara lebih jelas terkait hasil penelitian penulis sebagai berikut:

1. Kebanyakan mahasiswa berpendapat bahwa alasan belajar bahasa mandarin dikarenakan mereka tertarik untuk mempelajari bahasa mandarin dan kebudayaannya. Selain itu juga mereka beranggapan bahwa dengan mempelajari bahasa mandarin, dapat membuat mereka mendapatkan kesempatan untuk bersekolah di China dan mereka yakin bahwa bahasa mandarin sangat berguna untuk masa depan mereka.

2. Kesulitan yang sering mahasiswa hadapi dalam mempelajari bahasa mandarin yaitu kesulitan dalam melafalkan nada yang masih sering keliru, penguasaan tata bahasa yang kurang baik, penguasaan kosakata yang sangat sedikit, kesulitan dalam mengingat tulisan aksara mandarin sehingga kebanyakan dari mereka masih memerlukan bantuan hanyu pinyin dalam membaca tulisan aksara mandarin.

3. Kebanyakan dari mahasiswa berpendapat bahwa penghambat terbesar bagi mereka dalam upaya meningkatkan kemampuan berbahasa mandarin adalah tidak terciptanya suatu lingkungan yang mendukung dalam belajar bahasa mandarin sehingga menyebabkan mahasiswa kurang termotivasi untuk lebih giat lagi dalam melatih kemampuan diri berbahasa mandarin serta minimnya fasilitas yang ada di lingkungan prodi 
sebagai penunjang keberhasilan belajar.

4. Dalam pembelajaran Tata Bahasa, strategi yang sering mereka lakukan adalah strategi metakognitif dan sosial dan kadang-kadang juga melakukan strategi kognitif. Dengan adanya pemahaman dan menganalisa sebuah Tata Bahasa yang baik tentunya akan dapat berkomunikasi dengan baik pula. Dengan pengetahuan budaya secara khususnya dapat juga memahami secara dasar untuk mempelajari sebuah Tata Bahasa, selain itu pula perlu adanya perbandingan dengan bahasa ibu sebagai faktor pendukung dalam pemahaman sebuah Tata Bahasa.

\section{Saran}

Berdasarkan hasil penelitian yang diperoleh, peneliti memberikan saran sebagai berikut: (1) Untuk pembelajaran Pelafalan bahasa mandarin, mahasiswa sebaiknya perlu untuk lebih sering menggunakan bahasa mandarin dalam percakapan sehari-hari baik itu kepada teman sekelas maupun kepada dosen karena cara ini sangat membantu mereka untuk melatih pelafalan bahasa mandarin agar bisa lebih baik; (2) Untuk pembelajaran kosakata terutama dalam menguasai kosakata-kosakata baru, mahasiswa dapat melakukan latihan secara mandiri seperti sering menonton film atau drama Mandarin, kemudian mencatat kosakata baru yang belum pernah dipelajari, setelah itu mempelajari penggunaan kosakata tersebut dalam sebuah kalimat dengan bantuan aplikasi belajar bahasa mandarin, serta sering melakukan latihan dikte agar kosakata tersebut dapat lebih dikuasai; (3) bagi dosen pengajar diharapkan mampu menerapkan metode yang lebih inovatif agar mahasiswa dapat lebih cepat menguasai materi-materi yang diajarkan terutama dalam penguasaan pelafalan dan kosakata seperti memanfaatkan aplikasi-aplikasi pembelajaran berbasis online yang kreatif dan menarik perhatian mahasiswa dalam belajar; (4) bagi peneliti yang ingin mengkaji penelitian ini lebih lanjut, sebaiknya bisa memperhatikan kelemahan-kelemahan dalam penelitian ini, seperti angket dan soal tes yang diberikan kepada objek penelitian bisa dipersiapkan secara lebih baik dan lengkap serta bentuk soalnya dapat dikembangkan menjadi lebih variatif.

\section{DAFTAR RUJUKAN}

Bie, Hongying, Huang, Borong \& Wang, Lei (2018) 国际汉语教学汉字教学方法 与技巧(Pembelajaran Bahasa Mandarin Internasional - Metode dan Teknik Pengajaran Huruf Mandarin), Beijing Language and Culture University Press. Chen, Xi (2001) 汉字演化说略 (Sinopsis Evolusi Huruf Mandarin), Qunyan Press.

$\mathrm{Hu}$, Wenhua (2008) 汉字与对外汉字教 学 (Hanzi dan Pengajaran Huruf Mandarin Untuk Siswa Asing), Xuelin Press.

Huang, Borong \& Li, Wei (2014) 现代汉 语 (Bahasa Mandarin Modern), Peking University Press.

Huang, Jinjin (2000) 德國學生學習漢字 的情況及其學習策略 (Kondisi dan Strategi Pembelajaran Huruf Mandarin Pada Siswa Kewarganegaraan Jerman). 語言研究特刊 2000, p.323-27. 武漢: 國 際漢語教學學術研討會論文集。中德 雙方合作研究計畫人員交流, PPP 計畫 編號: 8801-ppp-19.

Jiang, Xin \& Zhao, Guo (2001) 初级阶 段外国留学生汉字学习策略的调查研 究, China Academic Journal Electonic Publishing House, Edisi ke-4.

Jiang, Xin (2000) 汉语作为第二语言学 习策略研究(Penelitian Tentang Strategi Belajar bahasa Mandarin Sebagai Bahasa Kedua), Language Teaching and Linguistic Studies Jornal, Vol 1, P61-68. 
Ke, Chuanren (2018) The Routledge Handbook of Chinese Second Language Acquisition, Routledge CRC Press.

$\mathrm{Li}$, Xiangping (2012) 汉字理论与应用

(Teori dan Praktek Huruf Mandarin, Jinan University Press.

Liem Vita Angela Handoko dkk (2019). Strategi pembelajaran kosakata bahasa mandarin pada aplikasi pembelajaran chineseskill. Universitas Kristen Petra.

Lin, Wenxiu (2011). 初级水平泰国学生 汉语语音学习策略研究 (Penelitian Strategi Pembelajaran Pada Siswa Dasar di Thailand), Nanjing University.

Liu, Songhao (2013) 第二语言习得导论 - - 对外汉语教学视角 (Panduan Akuisisi Bahasa Kedua-—Dari Sudut Pandang Pembelajaran Bahasa Mandarin Sebagai Bahasa Kedua, World Book Inc.

Lu Qinghe (2006) 实用对外汉语教学 语法 (Metode Pengajaran Tata Bahasa Mandarin Praktis), Beijing University Press.

Lu Zhou (2005). 美国大学生 (CIEE 项 目) 汉语口语学习策略的研究 (Penelitian Strategi Berbicara Mahasiswa di Amerika. Program CIEE), Huadong Normal University.

Peristera Hana (2013). Pembelajaran pelafalan bahasa Mandarin dengan metode Tracking dan Slow Motion Speaking Bagi Siswa Kelas 1 SMP
Kristen Pelita Nusantara Kasih Surakarta. Universitas Sebelas Maret.

Prof. Dr. Sri Anitah W. Strategi Pembelajaran (Modul 1).

Sung, K.-Y., \& Wu, H.-P. (2011). Factors influencing the learning of Chinese characters. International Journal of Bilingual Education and Bilingualism, 14(6), 683-700.

Tan, Teow Ghee \& Hoe, Foo Terng (2009) Vocabulary Learning Strategies of Students, Learning Mandarin as a Foreign Language, P181-190.

Wang, Zhenyan (2014). 印尼学生汉语 语音学习策略调查研究——以印尼四 所大学为例 (Strategi Pembelajaran Pelafalan pada Mahasiswa Indonesia - Studi Kasus pada 4 Universitas di Indonesia, Nanjing University.

Yan Shenghan (2004). 留学生汉语词汇 学习策略的研究 ( Penelitian Strategi Pembelajaran Kosakata Pada Siswa Asing, Beijing Languange and Culture Iniversity.

Yus Rusyana dan Samsur, 1976. Pedoman Penulisan Tata Bahasa Indonesia, Proyek Pengembangan Bahasa dan Sastra Indonesia dan Daerah, Bandung - Malang.

Zhou, Jian (2009) 汉字教学理论与方法 (Teori dan Metode Pengajaran Huruf Mandarin), Peking University Press. 